\title{
Urgences
}

\section{Le récit de Joachim (extrait)}

\section{Paul Chamberland}

Numéro 14, août 1986

Corps et jouissances

URI : https://id.erudit.org/iderudit/025264ar

DOI : https://doi.org/10.7202/025264ar

Aller au sommaire du numéro

Éditeur(s)

Urgences

ISSN

0226-9554 (imprimé)

1927-3924 (numérique)

Découvrir la revue

Citer ce document

Chamberland, P. (1986). Le récit de Joachim (extrait). Urgences, (14), 49-53. https://doi.org/10.7202/025264ar d'utilisation que vous pouvez consulter en ligne.

https://apropos.erudit.org/fr/usagers/politique-dutilisation/ 


$$
-
$$




\section{Le récit de Joachim (extrait)}

La douceur d'aimer me pousse à la perdition. Je les voudrais tous. Surprendre leur fragilité. Ils n'aiment pas ça, ça les agace. Leur inquiétude m'excite, je ne lâcherai pas. La perversion doit être tenue pour un sceau, porté sur l'inconnu du désir.

\section{Je suis noyé de sperme dans un champ de garçons.}

Un jour, sur le terrain de balle, des garçons - tout un groupe viennent et, m'ayant reconnu, se précipitent vers moi. Ils portent pour la plupart des survêtements aux couleurs vives. Ils se sourient d'un air entendu. Ils m'ont cerné. Je m'entends dire il y a longtemps que je n'ai pas été nourri. Deux garçons me font basculer, me voici étendu contre terre. Leur cercle se resserre. Je les regarde au-dessus de moi. Je les vois tous bander. Ils dégagent fièrement leur sexe et se masturbent, s'encourageant mutuellement, des plus petits aux plus grands. Les jets de sperme m'inondent bientôt le visage, la poitrine, les mains, que je tiens croisées sur ma poitrine. J'en suis tout recouvert. La juvénile semence envahit mes cellules, y propageant un courant d'extase si violent que je me dissous, me confonds à la terre. J'entends un garçon commenter, satisfait: une belle récolte en perspective, faudra venir voir nos petits. Plus tard dans la saison, de jeunes arbres magnifiques couvrent tout le champ. Je circule dans le réseau ligneux, activant la maturation des fruits. Je suis devenu un pur ruissellement de joie.

Joachim devient Joachim en soutenant jusqu'au bout la visualisation de la scène. La peur le met en alerte, et en surmontant la peur, il gagne une lucidité plus vive. Le vice au corps, la possession diabolique, le bûcher qui ne s'éteint pas, des représentations déjouées. Dans le phantasme pleinement déployé, les affects de honte, d'humiliation, d'abjection ont cessé d'être excitants. Ils sont étrangers, la pulsion n'est plus liée. La scène a lieu ailleurs que dans le lieu clos du sadomasochisme. Nous ne sommes pas, ni eux ni moi, dans l'histoire privée. Nous ne sommes pas dans l'histoire. C'est un rite que nous accomplissons. Leur exubérante jouissance, et ma soumission fascinée, répondent à l'appel du champ et de l'air où circule l'intense élément de la viridité. Tout comme moi, ils savent ce qu'il en est, nous agissons en exécutants éblouis de ce qui nous dépasse et 
nous comble. Tout, ici, aime, dans le déroulement d'un mystère. Rite agraire, archaïsme? Indéniable. Ou — son nom - Fête du Mai. Je ne suis ni un homme, ni une femme, ni même un taureau (vache) qu'on immole, mais le champ dans la transe ovulaire qu'exauce la crue de jeune génésie.

La perversion n'est qu'un sceau porté sur l'inconnu du désir. Briser les noeuds de scintillations glacées et toxiques. Refaire la jonction avec ce fond qui veut en nous la fécondité du rite amoureux. 


\section{Primevère}

décapsuler l'amande mâle de son tendre repli pour la porter aux lèvres comme l'efferverscence du jeune verd aux branches porte l'intrépidité morale, d'elle-même, est un printemps recueillir les enseignements d'Aphrodite, porter sa robe, son aura pétillements d'or natif, ne voyez-vous pas que l'arc d'Harmonie s'enthousiasme de la coupe de champagne aux lèvres oui je revivrai encore au lâché des confetti végétaux, aux mousses flottantes des semences, et à l'euphorie kinésique des petits garçons, recevant à l'éclat blanc de leurs cuisses le don du dieu qui les habite et leur ressemble, Dionysos

et ceci, oui, c'est la terre 


\section{Dionysos philosophe}

la semence du jeune prince malien explose dans la gueule de Dieu "le jet et la retombée des mots" quand le monde n'est peut-être qu'une conversation enjouée, "l'enfance de Dieu" "l'âme orgiaque, son sourire" atlantéen... "le ciel regardait sanglant et cruel"

l'anecdote cosmogonique recommence au ras des trottoirs en toutes saisons, apprenez à lire, mettez la bande urbaine en marche des propositions extrêmes sur la morale champ de ruines sont avancées, le troupeau s'émeut s'ameute aux hot lines

Sid Vicious Johnny Rotten Nina Hagen Jello Biafra, la panique est salubre, c'est "la nature mystique souillée par le vice, écumante" Caligula Néron Héliogabale Borgia, le sacré commande "le gaspillage de nos passions et de nos désirs" non, la vérité n'est pas bonne à dire, jamais, et ceux qui osent disparaissent souvent dans les broyeuses municipales... pour reparaître au dictionnaire quand le mal est fait rendez-vous à l'intersection Sade/Pasolini, les feux de circulation lâchent à jets continus lasers et décibels vaudous, les citadins slamment sous l'onde de choc érosismique, du fond de la peau les fantasmes bourgeonnent et font tatous mais la transgression déchire et démembre seulement, l'enveloppe de la vérité doit être ouverte pour que la langue danse

Ariane, accorde-moi tes petites oreilles

1. Les citations sont de Nietzsche. 